\title{
ОСОБЕННОСТИ УПОТРЕБЛЕНИЯ ВСПОМОГАТЕЛЬНОГО ГЛАГОЛА В ФОРМАХ ПЕРФЕКТА В 1-М ЛИЦЕ ЕДИНСТВЕННОГО ЧИСЛА В ДРЕВНЕРУССКИХ ГРАМОТАХ ХIV-ХVI ВВ.
}

\author{
THE USE OF AUXILIARY VERB IN THE 1ST PERSON SINGULAR \\ PERFECT VERBAL FORMS IN THE OLD RUSSIAN DOCUMENTS \\ OF THE 14-16TH CENTURIES
}

\author{
MACIEJ WARACZEWSKI
}

\begin{abstract}
AвSTRACт. This paper analyzes the use of perfect tense forms in a collection of Old-Russian charters: Testaments and Contractural Letters of the Russian Great and Appanage Princes of the $X I V-X V I$ centuries. A special attention has been paid to the connection between the presence of an explicit subject and an auxiliary verb and their strict mutual dependence has been proved.
\end{abstract}

Keywords: perfect, subject, Old-Russian language, comparative linguistics

Maciej Waraczewski, Uniwersytet im. Adama Mickiewicza w Poznaniu, Poznań - Polska, maciejwaraczewski@wp.pl

ORCID ID: 0000-0002-4424-3966

Древнерусская система прошедших времен подвергалась большим изменениям, в результате которых перфект стал единственным средством выражения прошлого, что постепенно приводило к вытеснению других времен. В целом, процесс хорошо исследован [см. Шульга 1982: 125; Кузнецов 1953: 245; Якубинский 1953: 241], но подробности как семантических, так и формальных преобразований, происходящих в его рамках, все еще не нашли своего точного объяснения. Многие авторы пытаются обнаружить семантические особенности перфекта, которые позволили ему принять на себя универсальное значение прошлого [см. Маркова 2013: 247-257; Маркова 2015: 224-226; Гаспаров 2003: 215-240], другие, в свою очередь, уделяют больше внимания его формальному аспекту. По нашему мнению, стоит проанализировать формы перфекта в контексте взаимосвязей, которые выступали между применением в предложении эксплицитно выраженного подлежащего и вспомогательного глагола (глагола-связки, связки) быти, который со временем был утрачен. На эту связь обращают внимание также Алексей Ивано- 
вич Соболевский [1907: 239-242] и Андрей Анатольевич Зализняк [2008: 240-249].

Ниже представлены результаты проведенного нами исследования, в котором анализу подверглись формы 1-го лица единственного числа перфекта в сборнике древнерусских документов - Духовных и договорных грамотах великих и удельных князей XIV-XVI вв. (далее - ДДГ). Все употребления 1-го лица единственного числа перфекта из вышеуказанного сборника в нашем исследовании подверглись статистическому анализу, при этом учитывались выступающие рядом подлежащие.

В 104 помещенных текстах обнаружено 765 форм перфекта в 1-м лице ед. ч., из которых 733 относятся к мужскому роду, 32 - к женскому. Глагол намного чаще употребляется со связкой - 646 раз, что составляет 84,3\%, чем без нее - 119 раз (15,7\%). Анализ двух временных периодов: XIV в. - первая пол. XV вв. (период I) и вторая пол. XV-XVI вв. (период II), показал, что в поздних текстах наблюдается тенденция к более частому пропуску вспомогательного глагола (13,7\% в текстах первого периода и 22,8\% в текстах второго периода), но все-таки даже в самых поздних текстах в значительном большинстве случаев глагол-связка встречается. Кроме того, его употребление не хаотично, а вполне системно, что и показывает дальнейший анализ.

Из 646 примеров, когда перфект в 1-м лице ед. ч. употреблен со связкой, только в 25 случаях рядом находится подлежащее (т.е. в менее чем в 4\%). В остальных 96\% случаев подлежащее опущено. В свою очередь, когда глагол употреблен без вспомогательного глагола, то в $86 \%$ случаев рядом выступает личное местоимение я/яз и только в 17 из 119 случаев рядом с глаголом нет ни связки, ни подлежащего. Эти данные представлены в таблице 1:

ТАБЛИЦА 1

\begin{tabular}{|l|c|c|}
\hline Связка & $\begin{array}{c}\text { Присутствие } \\
\text { Подлежащего }\end{array}$ & $\begin{array}{c}\text { Отсутствие } \\
\text { подлежащего }\end{array}$ \\
\hline Присутствие связки & 25 & 621 \\
\hline Отсутствие связки & 102 & 17 \\
\hline
\end{tabular}

Принимая во внимание эти данные, можно прийти к выводу, что, как правило, применение личного местоимения в функции подлежащего в 1-м лице ед. ч. влечет за собой пропуск вспомогательного глагола в перфекте; в то же время присутствие глагола-связки приводит к пропуску подлежащего. В свою очередь примеры, в которых одновременно ис- 
пользуются глагол-связка и местоимение, выступающее в функции сказуемого, являются отступлением от нормы, своего рода исключением. К исключениям также относятся примеры, в которых пропущены оба элемента. Все вышеуказанные примеры, относящиеся к исключениям, подверглись углубленному анализу с целью проверить, можно ли в этих случаях найти какие-либо закономерности.

Из 25 примеров, в которых одновременно употребляется глагол-связка и прямо выраженное подлежащее $я / я з$, можно выделить следующие случаи:

1) 18 раз в предложении выступает слово се, например: Се яз, князь великии Иванъ Василиевич всеа Руси, пожаловал есми детеи своих... [ДДГ 1950: 370];

2) 6 раз предложение имеет следующую структуру: яз, князь великий | имя князя | причастие на - | есмь без слова се, например: А на сеи грамоте яз, князъ великии Василии Дмитриевич, целовал есмь крестъ... [ДДГ 1950: 45].

Как видно, в 24 из 25 случаев предложение, в котором перфект в первом лице единственного числа употребляется как со связкой, так и с подлежащим, имеет строго определенную, официальную структуру, характерную для делового стиля. Кроме того, предложения такого типа выступают обычно в самом начале или конце текста, т.е. в местах, где чаще всего употребляются устойчивые деловые формулы. Обращается на это внимание в Истории русского литературного языка, в которой отмечается, что духовные грамоты характеризируются многими архаичными чертами книжного характера, что „особенно заметно в стабилизовавшихся начальных и концевых формулах грамот" [Кадькалов, Сердобинцев, Судавичене 1984: 64]. Особую роль формулировки Се яз подчеркивает Владимир Викторович Колесов в Древнерусском иитературном языке, описывая язык княжеских грамот. Автор сообщает о том, что в других грамотах намеренно избегается употребления авторского $я$, однако в княжеских грамотах оно встречается очень часто: „Все княжеские уставы XI-XII в. имеют формульное начало «Се яз, князь великий...»" [Колесов 1989: 123-124]. Правда, здесь речь идет о текстах более раннего периода, но принимая во внимание большую устойчивость данных формул, можно признать, что они употреблялись в неизмененном виде вплоть до XVI в., что находит отражение в анализируемых нами текстах. Об особенном употреблении личных местоимений в приложениях писал также Алексей Иванович Соболевский [1907: 239-242].

Из сказанного выше вытекает, что употребление (Се) яз в начале предложения не является признаком живого, активного процесса в рус- 
ском языке XIV-XVI вв., и все случаи употребления этой формулировки вместе с перфектом со связкой не предполагается возможным рассмотреть в морфо-синтаксическом контексте. Принимая во внимание, что $96 \%$ описываемых нами „исключений” - это именно сочетания такого типа, необходимо отметить, что это является скорее всего эффектом внеязыковых, чем языковых явлений, и оно ни в коем случае не может представлять собой препятствия для формулировки тезиса о том, что перфект со связкой в 1-м лице ед. ч. никогда не употребляется вместе с подлежащим.

Ни одна из приведенных выше ситуаций не происходит только в одном случае: .... яз, господине, тое твоее вотчины, Дмитрова и с волостми и со всем, как еси, господине, был мене пожаловал, отступияся есми, господине, тобе, Великому князю... [ДДГ 1950: 183].

Однако структура указанного выше предложения очень сложна, и подлежащее яз отделено от вспомогательного глагола другим предложением, которое выражено в другом (а именно во втором) лице единственного числа. По этому поводу кажется обоснованным предположение, что такое употребление подлежащего представляет собой скорее пример особенного логического ударения и не противоречит представленной выше гипотезе о тесной связи между присутствием подлежащего и употреблением глагола-связки.

Что касается тех случаев, в которых в предложении не употреблены ни вспомогательный глагол, ни подлежащее, то и здесь можно заметить несколько закономерностей, объясняющих нехватку этих элементов:

1) употребление вспомогательного глагола в предшествующем причастном обороте (7 раз), например: Господину, господарю моему, Великому князю Витовту, се язб, князь велики Иван Володимерович проньскыи, добиль есми челом и дался ему в службу... [ДДГ 1950: 68-69].

В приведенном выше примере на самом деле нельзя считать, что глагол в перфекте употреблен без связки. Правда, она не находится в его непосредственной близости, а предшествует другому, употребленному раньше глаголу, поэтому логичным кажется предположение о том, что она касается обеих форм на - . Это указывает также на синтаксическую особенность употребления перфекта, заключающуюся в том, что вспомогательный глагол не нуждается в повторении при условии, что если рядом с ним находятся две глагольные формы на - $\Omega$. Стоит отметить, что это редкий случай, так как обычно связка повторяется даже в том случае, если рядом стоят несколько глаголов в той же форме.

Итак, в большинстве случаев связка находится рядом с обоими глаголами. Лишь в одном случае это представляется другим образом: 
А которые есьми вотчины поимал у князей ярославских, и те вотчины сыну моему Федору, а сын мой Федор в том волен, хощет те вотчины за собою держать, хощет он отдать. А у которых князей ярославских их вотчин не имал, и сын мой Федор тех вотчин не отнимает у них, и сын мой Федор тех вотчин не отнимает у них, жен, и у детеи их, а отъедут к сыну моему Ивану или инуды куды-нибудь, и те вотчины сыну моему Федору [ДДГ 1950: 442].

Здесь вспомогательный глагол есьми употребляется только в первом предложении, что является достаточным для того, чтобы понять, что глагол имал во втором предложении тоже относится к первому лицу.

Вторая закономерность:

2) употребление подлежащего в предшествующей синтагме (6 раз): .... я тебе, и великого кнгазя, перепросил, с тобою взял любовъ... [ДДГ 1950: 163].

В указанных выше примерах отказ от употребления подлежащего в непосредственной близости не означает, что у глагола никаким образом не выражается лицо. Дело в том, что слово я/яз может относиться к более чем одному глаголу, если они употреблены в рамках одного предложения.

Представленные выше примеры подтверждают замеченные раньше особенности употребления древнерусского перфекта в 1-м лице ед. ч. Можно, конечно, также предположить, что эти особенности не имеют общелингвистического характера, а являются лишь результатом „предпочтения" одних форм определенными авторами, т.е. некоторые составители - по внеязыковым причинам - употребляют глаголы в перфекте с подлежащим, но без связки, а другие - со связкой без подлежащего. Однако несостоятельность данного утверждения можно доказать с помощью анализа дополнительных примеров из избранных текстов разных времен:

...так же и темъ, чемъ, брате, яз тобя пожаловал, дал ти есми в вудел, в вотчину удел дяди намего... [ДДГ 1950: 115];

Да коли есми з божіею волею достал своей отчины, города Смоленьска и земли Смоленьскіе, и яз тогды обещал поставити на Москве на посаде Девчь манастырь, а в нем храм во имя Пречистые да Происхожденіе честнаго креста, и иные храмы, а которые храмы В том манастыре поставити, и яз тому велел написати запись дяку своему Труфану Ильину своею рукою да дати печатнику своему Ивану Третьякову. А дати есми обещзал в том манастырь из своих сел дворияовых село или два... [ДДГ 1950: 415].

Указанные выше фрагменты грамот показывают, что употребление перфекта в 1-м лице ед. ч. со связкой или без нее не зависит ни от предпочтения автором одних форм другим, ни от семантики глагола (так, 
в грамоте № 100 в близком соседстве друг с другом находятся глагол обещзал со связкой и тот же глагол без связки). Фрагментов, в которых присутствуют вместе как формы со связкой, так и формы без нее, намного больше, и в данном исследовании не удалось установить никакой другой морфо-синтаксической зависимости, кроме присутствия эксплицитно выраженного личным местоимением подлежащего.

На основании представленных выше данных возможно сделать следующие выводы:

1) наличие подлежащего, выраженного местоимением я/яз для 1-го лица ед. ч. влечет за собой отсутствие вспомогательного глагола;

2) наличие вспомогательного глагола влечет за собой отсутствие эксплицитного подлежащего.

Отклонения от описываемых закономерностей очень редки (менее $5 \%)$, и их можно объяснить причинами следующего характера:

1) синтаксического: если подлежащее и сказуемое разделены какой-либо сложной синтаксической конструкцией, глагол-связка все-таки может употребляться; подлежащее или связка могут не повторяться и относиться к более чем одному сказуемому, особенно, если они находятся близко друг к другу;

2) внеязыкового: определенные конструкции (например, приложения типа Се яз | имя князя) требуют употребления вспомогательного глагола, даже если в предложении уже появляется подлежащее, что вытекает из специфических стилевых черт данных текстов.

Принимая во внимание все сказанное выше, можно ответить на вопрос о причинах столь высокого уровня регулярности употребления форм перфекта, а именно наблюдаемой зависимости между наличием подлежащего и присутствием/отсутствием вспомогательного глагола. Чтобы добиться этой цели, необходимо сначала найти ответ на вопрос о направлении этой связи, т.е. установить, зависит ли присутствие подлежащего от присутствия связки, или же присутствие связки обусловлено употреблением в предложении подлежащего.

Как уже отмечалось ранее, изменения в области употребления перфекта главным образом заключаются в утрачивании им вспомогательного глагола. Из приведенных выше данных вытекает также, что в случае отсутствия глагола-связки в подавляющем большинстве случаев в предложении появляется подлежащее и, наоборот, при отсутствии подлежащего появляется глагол-связка. В более поздних периодах в грамотах снижается употребление глагола-связки, в то же время увеличивается употребление подлежащего. Таким образом, можно сказать, что подлежащее постепенно становится неким замещением вспомогательного глагола. В связи с этим необходимо выяснить, какие элементы упо- 
требления подлежащего и какие части сложного прошедшего времени являются общими, позволяющими им „обмениваться" своей функцией.

Факт отказа от употребления личного местоимения для названия субъекта действия в 1-м (и 2-м) лице в древнерусском языке общеизвестен. Как отмечает Алексей Никитич Стеценко,

личное местоимение, выступавшее в роли подлежащего при сказуемом, выраженном глаголом настоящего, прошедшего и будущего времени в 1-м или 2-м лице, обычно отсутствовало, так как сама форма сказуемого глагольной флексией указывала на действующее лицо [Стеценко 1972: 21].

Эти местоимения даже определяются как „избыточные” [Стеценко 1972: 9]. При этом стоит подчеркнуть, что именно глагол-связка представляет собой тот компонент перфекта, который содержит в себе значение лица, поскольку глагольная форма на $-\imath$ передает только информацию о семантике, роде и числе глагола.

Несмотря на изначальную „избыточность” местоимений со временем они становятся необходимым компонентом предложения в древнерусском языке. Начало этого длительного процесса можно проследить на основании тех примеров, в которых личное местоимение выступает в древнейших текстах. K факторам, благоприятствующим употреблению местоимений, исследователи относят, прежде всего, наличие особого ударения и необходимость четко разграничить действующие лица. В таком случае местоимение указывает не только лицо, но и является знаменательным элементом [Стеценко 1972: 187-188]. В большинстве работ обращается внимание преимущественно на стилистический аспект употребления местоимения-подлежащего. Итак, согласно Алексею Стеценко, нормой для древнерусского языка вплоть до XVII в. является не двусоставное, а определенно-личное предложение, в котором отсутствует прямо выраженное подлежащее и выражение лица содержится в форме глагола. Однако местоимения в функции подлежащего начинают употребляться с XIII в., но рост их применения был очень медленным. Такая ситуация отражена во всех древнерусских памятниках, независимо от их стилистической принадлежности, а также в русских говорах, что свидетельствует об огромной устойчивости древней традиции.

В Исторической грамматике русского языка [Борковский, Кузнецов 2010: 322-324] особое внимание уделяется текстам деловой письменности. Содержащиеся в ней сведения об употреблении личных местоимений в 1-м и 2-м лице в памятниках XI-XIII вв. следующие:

1) они, как правило, не употребляются в изъявительном наклонении;

2) их употребление вызвано необходимостью выделить действующее лищо среди других лиц; 
3) в духовных и договорных грамотах особенно часто наблюдается употребление местоимения я, что объясняется требованиями стиля;

4) употребление личного местоимения яз в конструкции се яз... имеет устойчивый характер.

Эти закономерности находят полное отражение в изученных нами текстах, если учесть, что вспомогательный глагол в какой-то степени заменяет в предложении подлежащее, по крайней мере в области указания лица. И именно в таком более широком контексте, то есть на фоне преобразований целой синтаксической системы древнерусского языка, следует рассматривать описываемые в настоящей статье явления.

Стоит также подчеркнуть, что указанное явление свидетельствует о том, что связка в описываемый период совсем утратила свое первоначальное грамматическое значение части сложного прошедшего времени и сохранила в себе лишь личное значение.

Таким образом, можно утверждать, что употребление личного местоимения приводит к утрате глагола-связки в формах перфекта. По описанным выше причинам в предложениях все чаще начинает употребляться подлежащее, эксплицитно выраженное местоимением. В связи с этим, применение вспомогательного глагола является избыточным, так как лицо глагола находит свое отражение в подлежащем. Эту мысль выражает также Андрей Анатольевич Зализняк, определяя личные местоимения и связки как „функциональные синонимы” [Зализняк 2008: 240].

Особое внимание необходимо также уделить тому факту, что „в XVXVI вв. наблюдается некоторый рост употребления личных местоимений при формах изъявительного и сослагательного наклонений [...] в деловой письменности [...] без логического ударения на местоимении" [Зализняк 2008: 203]. Данный факт, касающийся текстов анализируемого нами периода, находит свое полное отражение в формах перфекта в Договорных и духовных грамотах..., доказательством чего являются многочисленные примеры, приведенные в аналитической части настоящей работы. Стоит также отметить, что некоторые из тех примеров одновременного употребления вспомогательного глагола и личного местоимения можно также отнести к случаям употребления „логического ударения”, однако его синтаксическое выражение является уникальным. Согласно сведениям Виктора Ивановича Борковского и Петра Саввича Кузнецова, в целях выделения действующего лица среди других в предложении применяется личное местоимение. Предложение становится двусоставным, тем самым заменяя предложения определенно-личного типа. Однако в формах перфекта в Договорных и духовных грамотах... личное местоимение употребляется чаще, даже тогда, когда нет необходимости 
выделять исполнителя действия. Поэтому в случаях возникновения такой необходимости применяется другой способ, а именно: кроме личного местоимения употребляется также вспомогательный глагол быти в личной форме. Благодаря этому лицо глагола выражается два раза подлежащим и глаголом-связкой. Таким образом, в грамотах XIV-XVI вв. совместное употребление подлежащего и вспомогательного глагола выполняет функцию, ранее выполняемую только личным местоимением: принятие логического ударения с целью указать на действующее лицо.

\section{Библиография}

Борковский В. И., Кузнецов П. С. 2010. Историческая грамматика русского языка, Москва: Издательская группа URSS.

Гаспаров Б. 2003. Наблюдения над употреблением перфекта в древнецерковнославянских текстах, „Русский язык в научном освещении”, № 1 (5).

Зализняк А. А. 2008. Древнерусские энклитики, Москва: Изд-во Языки славянских культур.

Кадькалов Ю. Г., Сердобинцев Н. Я., Судавичене Л. В. 1984. История русского литературного языка, Ленинград: Просвещение.

Колесов В. В. 1989. Древнерусский литературный язык, Ленинград: Издательство Ленинградского университета.

Кузнецов П. С. 1953. Историческая грамматика русского языка. Морфология, Москва: Издательство Московского университета.

Маркова Т. Д. 2013. Древнерусский перфект в аспекте реализации функционально-семантической категории темпоральности, „Вестник Челябинского государственного педагогического университета", № 1.

Маркова Т. Д. 2015. Русский перфект как лингвокультурный феномен, электронный pecypc: http://libweb.kpfu.ru/publication/papers/Baudouin/Baudouin_2015_1/ Baudouin_2015_1_224_226.pdf (доступ 3.11.2016).

Соболевский А. И. 1907. Лекцции по истории русского языка, Москва: Университетская типография.

Стеценко А. Н. 1972. Исторический синтаксис русского языка, Москва: Высшая школа.

Шульга М. В. (ред.) 1982. Историческая грамматика русского языка. Морфология. Глагол, Москва: Академиздатцентр Наука.

Якубинский Л. П. 1953. История древнерусского языка, Москва: Государственное учебно-педагогическое издательство Министерства просвещения РСФСР.

\section{Условные сокращения}

ДДГ - Бахрушин С. В. (ред.) 1950. Духовные и договорные грамоты великих и удельных князей XIV-XVI bв., подготовил к печати Л. В. Черепнин, Москва-Ленинград: Издательство АН СССР. 
